\title{
Comparative results of endoscopic and open methods of vein harvesting for coronary artery bypass grafting: a prospective randomized parallel-group trial
}

Alexander Chernyavskiy ${ }^{1}$, Alexander Volkov ${ }^{1}$, Oleg Lavrenyuk ${ }^{1}$, Igor Terekhov ${ }^{1}$ and Yulia Kareva ${ }^{1,2^{*}}$

\begin{abstract}
Background: We compared wound complications between endoscopic and open great saphenous vein harvesting for coronary artery bypass surgery.

Methods: A total of 228 consecutive patients were prospectively randomized into two groups: open vein harvesting $(\mathrm{OVH}), 115$ patients; and endoscopic vein harvesting (EVH), 113 patients. Each group was assessed for post-operative wound complications, pain intensity, and neuropathy in the early post-surgical period. Lymphoscintigraphy of the lower limbs as well as morphological studies of vein walls using light and electron scanning microscopy were performed.

Results: Vein harvesting time was shorter for $\mathrm{EVH}$ than $\mathrm{OVH}$ : $31.8 \pm 6.2 \mathrm{~min}$ and $40.3 \pm 15.8 \mathrm{~min}$, respectively $(p<0.01)$. There were fewer complications after vein harvesting in the $\mathrm{EVH}$ group $(11.5 \%)$ than in the OVH group $(44.4 \%)(p=0.001)$. Multivariate analysis showed that diabetes mellitus was the only risk factor for post-surgical complications after $\mathrm{OVH}$ (odds ratio $=3.95 \%$; $95 \%$ confidence interval 1.03-8.6). Lymphoscintigraphic data in the $\mathrm{EVH}$ group did not demonstrate considerable disturbances in lymph drainage after surgery. In the OVH group, the accumulation of radiopharmaceutical drugs in the lymphatic nodes reduced two-fold $(p \leq 0.001)$. Histological evaluation of vein samples did not show considerable damage to the vein wall in either group.
\end{abstract}

Conclusions: Using electron microscopy of vein fragments, this study demonstrated that EVH reduces wound complications and provides good-quality conduits.

Keywords: Endoscopic vein harvesting, Coronary artery bypass surgery

\section{Background}

The great saphenous vein (GSV) remains one of the most commonly used conduits due to its ease of harvesting, availability, and versatility [1]. Traditional harvesting of the GSV involves the open-vein technique, which requires an extended leg incision. This technique is associated with a significant morbidity rate, and wound complications occur in $2-24 \%$ of cases [2, 3].

Minimally invasive techniques such as endoscopic vein harvesting $(\mathrm{EVH})$ have therefore been developed to

\footnotetext{
* Correspondence: julia11108@mail.ru

${ }^{1}$ Novosibirsk Research Institute of Circulation Pathology, Rechkunovskaja str. 15, 630055 Novosibirsk, Russia

${ }^{2}$ Stroiteley str., 9, 46, Novosibirsk, Russia
}

reduce post-coronary artery bypass grafting (CABG) leg wound complications. Currently, EVH is the method of choice in many centers as it allows lower post-surgical complication rates compared to the open method $[2,4,5]$. Although long-term graft patency following EVH has been questioned [6], cohort studies have reported that the technique is safe [7] and effective.

The possibility of using lymphoscintigraphy to evaluate the lymphatic system of the lower limb after vein harvesting for coronary artery bypass surgery has been reported previously [8]. Nevertheless, the state of the lymphatic system after vein harvesting is still poorly studied.

Currently, there is no consensus regarding the integrity and quality of the conduit following vein harvesting, 
which can have various impacts on the vein wall $[9,10]$. With this in mind, we studied the initial state of the venous conduit, peri-operative vein damage, and postoperative wound complications using two methods of GSV harvesting.

\section{Methods}

The present study was designed as a prospective, parallelgroup trial to assess wound complications in two groups of patients. The study was approved by the local ethics committee, and conducted from 2010 to 2012, in compliance with the approved protocol and in accordance with standard operating procedures. Informed consent was obtained from all patients in accordance with our institutional research ethics review board guidelines. The study included 228 patients diagnosed with ischemic heart disease who underwent coronary artery bypass surgery from 2010 to 2012 at the Novosibirsk Research Institute of Circulation Pathology. The primary study end point was to identify differences in the clinical and functional condition of the lower limbs after the two methods of vein harvesting. The sample size required to address the primary end point was calculated on the basis of differences in lower limb wound complications in previous studies involving patients treated with EVH and OVH [11]. Assuming a $15 \%$ improvement with the EVH method and applying the variance seen in our patients, we anticipated a sample size of 113 per group to demonstrate a significant difference $(p<0.05)$ at a power of $90 \%$ and with a $5 \%$ dropout rate.

Randomization to either the open vein harvesting $(\mathrm{OVH})$ group $(n=115)$ or the EVH group $(n=113)$ was performing in blocks of 10 with an allocation ratio of 1:1 using sequentially numbered, opaque, sealed envelopes. The designated study coordinator, who was not involving in filed procedures, was responsible for the preparation of the randomization list.

Inclusion criteria: subjects with multivascular lesions of the coronary artery who were suitable for coronary artery bypass surgery.

Exclusion criteria: patients requiring urgent coronary artery bypass surgery with unstable hemodynamics; previous coronary artery bypass surgery; chronic venous insufficiency C4-C6 according to the CEAP classification; and previous limb surgery.

All veins were harvested by experienced surgeons with previous experience of more than 100 procedures using both OVH and EVH.

Wound assessment was completed daily by a specialist wound nurse and a research team for the first 7 days after discharge.

\section{Open vein harvesting}

OVH was performed using a continuous incision under direct visualization. The GSV was identified two-fingers proximal to the medial malleolus according to standard practice. The vein was harvested using Metzenbaum scissors, and a continuous incision was made along the route of the vein. Care was taken not to traumatize the nerve, vein, or its branches. Vein branches were ligated with titanium clips. The wound was closed in layers with continuous 2-0 Polysorb sutures and 3-0 skin sutures. Immediately after vein harvesting, the lower leg was tightly bandaged, and elastic stockings were used in all patients after the operation.

\section{Endoscopic vein harvesting}

EVH was performed through minimal incisions using a Vasoview 6 system with $\mathrm{CO}_{2}$ insufflation into the closed cavity.

The vein was identified on the medial tibial border through a $3-\mathrm{cm}$ incision just below the knee as per standard practice. It is significantly easier to harvest vein conduits using EVH from the thigh due to the size and positioning of the endoscopic equipment and hence the ease of access to the vein. The incision site was sealed using a balloon port to create a tunnel inside the leg. $\mathrm{CO}_{2}$ insufflation was then commenced at $12 \mathrm{mmHg}$ of pressure with a $3 \mathrm{~L} / \mathrm{min}$ flow rate. A dissection tip cannula was introduced inside the tunnel to isolate the vein and its branches. A second unit with cautery was inserted via the port to cut and seal the tributary branches. A $1-\mathrm{cm}$ skin incision was made near the groin to ligate the distal end of the GSV and remove the vein, which was checked for leakage. The branches were tied with titanium clips, and necessary repairs were performed using 7-0 Prolene sutures. The wound was closed with 3-0 skin sutures. Immediately after vein harvesting, the lower leg was tightly bandaged, and elastic stockings were used in all patients after the operation.

After vein harvesting, a standard CABG procedure (cardiopulmonary bypass and cardioplegia) was performed.

The analysis of intraoperative data included: vein harvesting time point (total vein harvesting time - total time spent harvesting the vein, preparation of the vein for bypass surgery, and suturing wound time; vein harvesting time - only the time spent harvesting the vein, without preparation time and time spent suturing the wound; vein preparation time - the time spent on clipping the inflows to the veins and the closure of defect), wound closure time, harvested conduit length, and post-operational incision length on the lower limb. Assessment of the clinical state of the limb in the early post-surgical period included the following factors: wound healing and the frequency and intensity of post-surgical complications. In order to identify post-operational edema of the lower limb, the circumference at three levels before surgery and on day 7 following surgery was measured. Post-operative lymphedema was defined as an apparent increase in 
limb volume compared to the pre-operative status accompanied by induration of the surrounding tissues. Lymphorrhea was defined as the leakage of lymph from the wound after surgery. Pain intensity in the lower limb was established on the basis of a digital rating scale from 0 to $10(0=$ no pain to $10=$ unbearable pain $)$.

Evaluation of the initial and post-operative state of the lymphatic drainage in the lower limb was performed on the basis of radionuclide lymphoscintigraphy in 41 patients $(\mathrm{OVH}=18$ [43.9\%] patients, $\mathrm{EVH}=23$ [56.1\%] patients).

Lymphoscintigraphy was performed on the day before surgery and on day 7 after surgery. Drug evacuation from the inguinal lymphatic nodes was assessed $1 \mathrm{~h}$ after the patient began walking. In order to evaluate the resulting images, a scintigram point system was developed depending on the degree of disturbances from Grade 0 (no disturbances) to Grade 3 (expressed disturbances).

Morphostructural evaluation of the wall state of the GSV was performed in 161 patients $(\mathrm{OVH}=83$ [51.6\%], $\mathrm{EVH}=78[48.4 \%])$ using light and scanning electron microscopy. The GSV samples were used as materials for histopathological studies. Vein fragments with dimensions of 5-7 mm were immobilized in $10 \%$ formalin solution. Five $\mu \mathrm{m}$ thick sections were stained using hematoxylin and eosin and van Gieson's stain with additional staining of elastic fibers by Weigert's resorcinfuchsin. The endothelial lining was studied by scanning electron microscopy. The uniformity of the endothelial layer, deformation and desquamation of endothelium and polymorphism, and platelet reactivity were assessed.

\section{Statistical analysis}

Statistical analysis was performed with Statistica 6.0 software (Statsoft, USA). Results were shown as mean values ( \pm standard deviation) for quantitative values or as values and percentages for qualitative values. In order to detect dependence between the studied parameters, we performed the Spearman ratio of rank correlation as well as the odds ratio (OR) and absolute risk calculation. In order to calculate odds ratios, the $95 \%$ confidence interval $(\mathrm{CI})$ was calculated. $p$-values $<0.05$ were considered statistically significant.

\section{Results}

The groups did not differ with respect to most of the studied pre-operative characteristics except for atherosclerosis of the lower extremities, which was observed more frequently in the EVH group (20 patients [17.7 \%]) than in the OVH group (8,7 \%), $p=0.008$ (Table 1).

No cases of conversion to $\mathrm{OVH}$ were reported during the study. The average number of bypassed coronary arteries in the $\mathrm{OVH}$ group was $2.7 \pm 0.6$, whereas in the EVH group it was $2.8 \pm 0.6(p=0.117)$. The intra- operative data of patients from both groups are shown in Table 2. As can be seen from the table, almost all of the studied parameters were different between the two groups.

Assessment of post-surgical complication frequencies revealed that the total number of patients with postoperative complications was $44.4 \%$ in the $\mathrm{OVH}$ and $11.5 \%$ in the EVH group $(p<0.01)$ (Table 3). Post- operative complications were more frequent in the $\mathrm{OVH}$ group, especially lymphorrhea $(p=0.033)$, lymphedema $(p=0.001)$, post-surgical diastasis $(p=0.046)$, paresthesia $(p=0.003)$, and inflammatory changes $(p=0.011)$.

Correlation analysis in the OVH group detected statistically significant relationships between complications and diabetes mellitus $(p=0.04)$. Regression analysis of post-surgical complications in the OVH group identified diabetes mellitus as the only risk factor. Diabetes mellitus increased the probability of complications by threefold (OR = 3, 95 \% CI 1.03-8.6).

There were statistically significant differences in the levels of pain experienced between patients in the two groups in the post-operative period. In the EVH group, $47.8 \%$ of subjects experienced no pain ( 0 points), compared to only $28.7 \%$ of patients in the OVH group $(p<0.003)$. The probability of experiencing pain in the OVH group during the post-operative period was 2.3 times higher than in the EVH group $(\mathrm{OR}=2.3,95 \%$ CI $1.3-3.9, p<0.05)$.

Radionuclide lymphoscintigraphy showed that in the EVH group, the accumulation of radioactive drugs in the inguinal lymphatic nodes of the limb reached $17.87 \pm$ 11.95 , and $16.22 \pm 9.75$ after surgery $(p=0.34)$. In the $\mathrm{OVH}$ group, the accumulation of radioactive drugs was

Table 1 Comparative subject characterization

\begin{tabular}{llll}
\hline Parameters & $\mathrm{OVH}(n=115)$ & $\mathrm{EVH}(n=113)$ & $p$ \\
\hline Male, n(\%) & $95(82.6 \%)$ & $93(82.3 \%)$ & 0.169 \\
Age, years & $60 \pm 8.1$ & $61 \pm 7.4$ & 0.951 \\
CCS-class & $2.8 \pm 0.68$ & $2.9 \pm 0.84$ & 0.49 \\
NYHA-class & $2.8 \pm 0.7$ & $2.8 \pm 0.83$ & 0.83 \\
Weight, kg & $85.7 \pm 14.1$ & $82.9 \pm 15.2$ & 0.107 \\
Height, cm & $169.6 \pm 7.8$ & $168.1 \pm 8.2$ & 0.130 \\
Body weight index, kg/m ${ }^{2}$ & $29.70 \pm 3.88$ & $29.06 \pm 4.81$ & 0.181 \\
Obesity ${ }^{\mathrm{a}}[\mathrm{n}$ (\%)] & $14(12.2)$ & $14(12.4)$ & 0.450 \\
Diabetes mellitus [n (\%)] & $20(17.4)$ & $21(18.6$ & 0.323 \\
Lower limb atherosclerosis [n (\%)] & $10(8.7)$ & $20(17.7)$ & 0.008 \\
Arterial hypertension [n (\%)] & $109(94.8)$ & $95(84.1)$ & 0.075 \\
LV EF (\%) & $55 \pm 13.66$ & $55.6 \pm 13.67$ & 0.82 \\
EurosCORE & $5.5 \pm 0.7$ & $5.6 \pm 2.2$ & 0.65 \\
\hline CCS Canadian Cardiovascular Socity
\end{tabular}

CCS Canadian Cardiovascular Society grading of angina pectoris, LVEF left ventricular ejection fraction, NYHA New York Heart Association; Note $-{ }^{\mathrm{a}}$ by BWI - for males $>32$, for females $>34$ 
Table 2 Intraoperative results of great saphenous vein harvesting

\begin{tabular}{llll}
\hline Parameters & $\begin{array}{l}\mathrm{OVH} \\
(n=115) \\
\mathrm{M} \pm \mathrm{SD}\end{array}$ & $\begin{array}{l}\mathrm{EVH} \\
(n=113) \\
\mathrm{M} \pm \mathrm{SD}\end{array}$ & $p$ \\
\hline Total vein harvesting time, min & $40.3 \pm 15.8$ & $31.8 \pm 6.2$ & 0.01 \\
Vein harvesting time, min & $18.3 \pm 7.6$ & $24.7 \pm 5.5$ & 0.03 \\
Post-surgical wound closure time, min & $21.1 \pm 8.5$ & $3.5 \pm 0.7$ & 0.002 \\
Time of vein preparation, min & $0.9 \pm 1.5$ & $3.7 \pm 1.3$ & 0.03 \\
Harvested venous conduit length, cm & $31.6 \pm 9.4$ & $37.3 \pm 4.2$ & 0.04 \\
Skin incision length, cm & $35.4 \pm 10.2$ & $6.3 \pm 0.9$ & 0.001 \\
\hline
\end{tabular}

somewhat higher, reaching $20.89 \pm 11.53$. The lymphoscintigraphy findings on day 7 after surgery showed a reduction in radioactive drug accumulation $(9.78 \pm 7.02$, $p \leq 0.001$ ).

According to the pre-surgical lymphoscintigraphy data, there were two patients in the EVH group with an insignificant degree of lymphatic drainage failure, while two patients in the OVH group had similar changes. In the post-operative period in the EVH group $(n=23)$, there were eight $(34.8 \%)$ patients with lymphatic drainage dysfunction (seven [30.4\%] insignificant, one [4.3\%] moderate), while in the $\mathrm{OVH}$ group there were 17 (94.4\%) patients with similar issues (four [22.2\%] insignificant, five [27.7 \%] moderate, eight [44.4\%] severe) (Fig. 1).

In the OVH group $(n=18)$ after surgery, an insignificant degree of change was observed in four $(22.2 \%)$ patients, moderate change in five $(27.8 \%)$, and severe change in eight (44.4\%) (Fig. 2).

Thus, the total numbers of patients with lymphatic drainage disturbances in the $\mathrm{OVH}$ and $\mathrm{EVH}$ groups were $17(94.4 \%)$ and eight $(34.8 \%)$, respectively $(p=0.001)$.

When comparing lymphoscintigraphy data and clinical manifestations of lymphatic drainage disturbances after surgery (early lymphatic drainage and lymphorrhea), deviations were detected in nine patients (50\%) in the $\mathrm{OVH}$ group $(n=18)$ (seven cases of lymphatic drainage

Table 3 Postoperative complications

\begin{tabular}{llll}
\hline Parameters & $\begin{array}{l}\text { OVH } \\
(n=115)\end{array}$ & $\begin{array}{l}\text { EVH } \\
(n=113)\end{array}$ & $p$ \\
\hline Hematoma & $2(1.7 \%)$ & $4(3.5 \%)$ & 0.397 \\
Lymphorrhea & $7(6.1 \%)$ & $1(0.9 \%)$ & 0.033 \\
Postoperative lymphedema & $36(31.3 \%)$ & $4(3.5 \%)$ & 0.001 \\
Skin diastasis & $4(3.5 \%)$ & $0(0 \%)$ & 0.046 \\
Post-surgical wound infection & $1(0.9 \%)$ & $0(0 \%)$ & 0.322 \\
Paresthesia & $17(14.8 \%)$ & $4(3.5 \%)$ & 0.003 \\
Soft tissue inflammation & $15(13.0 \%)$ & $5(4.4 \%)$ & 0.011 \\
Number of subjects with complications & $51(44.4 \%)$ & $13(11.5 \%)$ & 0.001 \\
\hline
\end{tabular}

and two of lymphorrhea). In the EVH group $(n=23)$, these complications were not detected in any patients.

The data on structural damage of the vein wall are presented in Table 4. Focal endothelial layer desquamation predominantly along the length from 20 to $250 \mu \mathrm{m}$ was detected in 30 cases (36.1\%) in the OVH group and in 23 cases $(29.4 \%)$ in the EVH group $(p=0.37)$. Intimal ruptures occurred in the fibrous-thickened internal later in the perpendicular-longitudinal and circular-longitudinal directions relative to the vein lumen axis (23 patients [27.7\%] in the OVH group compared to 19 [24.4\%] in the EVH group, $p=0.63$ ).

Vein dissection was isolated and predominantly related to EVH cases (5 [6.4\%], $p=0.02$ ).

Vein vascular wall changes were rarely isolated, and more often were accompanied by other damage such as rupture or dissection (37 patients [44.6\%] in the $\mathrm{OVH}$ group compared with 32 [41 \%] in the EVH group, $p=0.65)$. The EVH method included coagulation of the vein branches; therefore, specific changes in the vein wall, such as perivascular soft tissue coagulation, were detected by histopathological analysis. Coagulation of paravascular tissue was observed in just seven $(8.9 \%)$ patients in the EVH group $(p=0.004)$.

Correlation analysis showed direct dependence between initial changes of the GSV and the extent of damage during $\mathrm{OVH}(p=0.03)$ and $\mathrm{EVH}(p=0.02)$, which allowed us to determine the risk of damage in the event of mild initial changes ( $A R=32 \%, 95 \%$ CI 20-44), moderate changes (AR $=75 \%, 95 \%$ CI 63-89), and severe changes ( $\mathrm{AR}=87 \%$, $95 \%$ CI 77-97).

\section{Discussion}

$\mathrm{CO}_{2}$ insufflation is used during $\mathrm{EVH}$ to create a closed working tunnel for vein preparation and harvesting. The recommended $\mathrm{CO}_{2}$ pressure is between 10 and $15 \mathrm{mmHg}$. Complications caused by $\mathrm{CO}_{2}$ insufflation are rare. Chiu et al. showed that significantly more $\mathrm{CO}_{2}$ can be detected by transesophageal echo in the inferior cava during $\mathrm{EVH}$ with a working pressure of $15 \mathrm{mmHg}$ [12-15]. Knowing this, we did not exceed a pressure of $10-12 \mathrm{mmHg}$. Therefore, specific complications associated with $\mathrm{CO}_{2}$ insufflation were not observed in this study, although we did not carry out specific examinations to identify them (e.g. transesophageal echocardiography).

The obtained data demonstrated that the method of vein harvesting used has a significant impact on the post-surgical wound complications experienced by patients, which is in accordance with the results of other studies $[4,16,17]$. Fewer wound complications were observed in the EVH group, with an absence of significant differences between the two groups according to the frequency of obesity and diabetes mellitus. At the same 


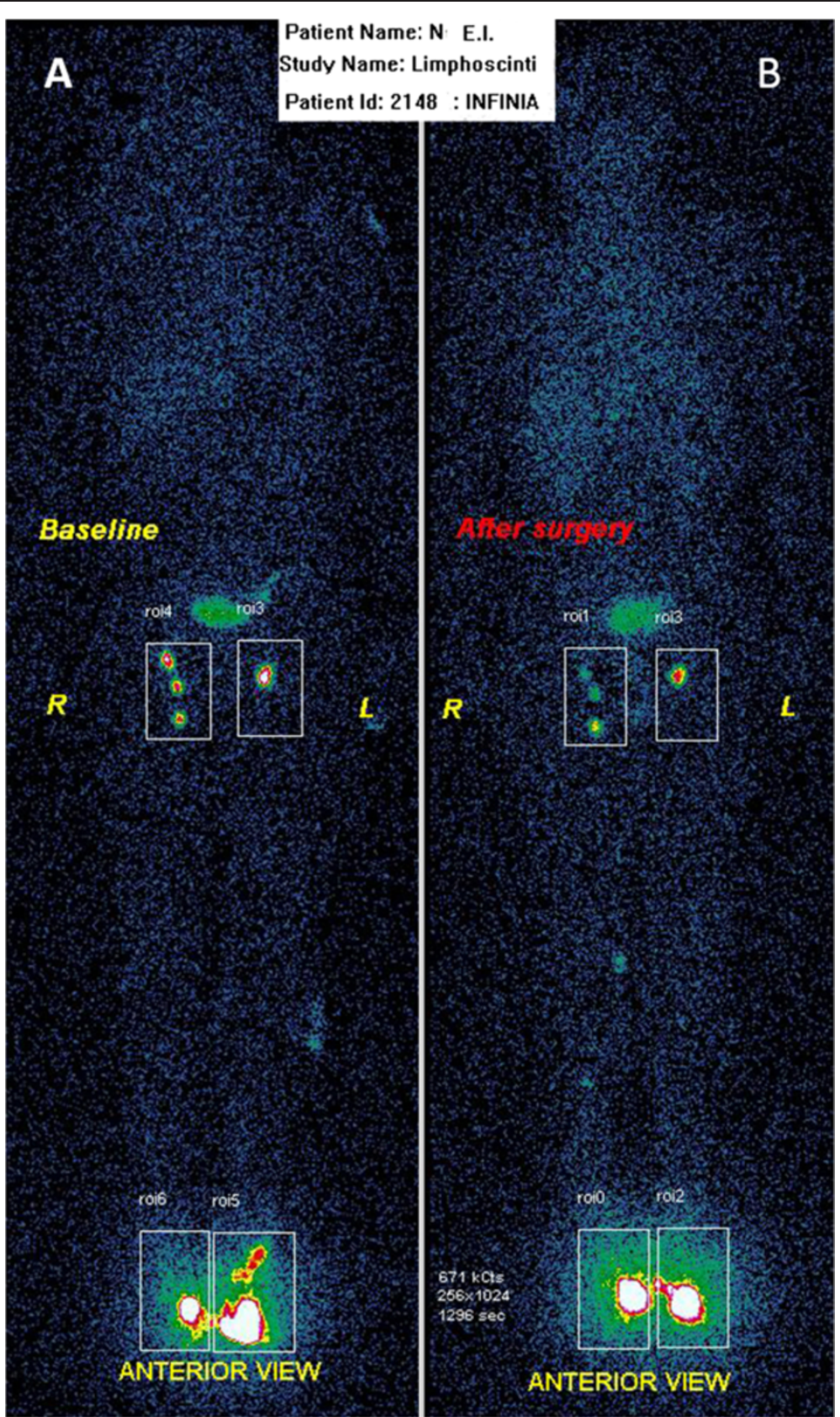

Fig. 1 Lymphoscintigrams before the surgery (a) and on Day 7 after the endoscopic vein harvesting on the right lower limb (b)

time, diabetes mellitus was an independent risk factor of post-surgical complications in the OVH group.

According to the results of the present study, the risk of paresthesia in the lower limb increased by 4.7 times in the OVH group. The higher percentage of complications in the OVH than the EVH group was accounted for by more frequent early lymphatic drainage. Thus, in the EVH group, according to the findings of previous studies, lymphatic drainage was observed in approximately $10-12 \%$ of patients [18]. However, in the present study, it was only observed in $4.5 \%$ of patients. The number of cases of lymphorrhea was higher (6.1\%) in the OVH group.

Another important aspect of surgical therapy is the degree of pain experienced by the patient after surgery. For patients, the reduction of post-surgical pain is the best predictor of satisfaction with surgery. Our study showed significantly lower intensities of post-surgical pain in the EVH group than in the OVH group, which is in accordance with the results of other studies.

Immediate patient satisfaction is important when assessing vein harvesting techniques. However, conduit quality 


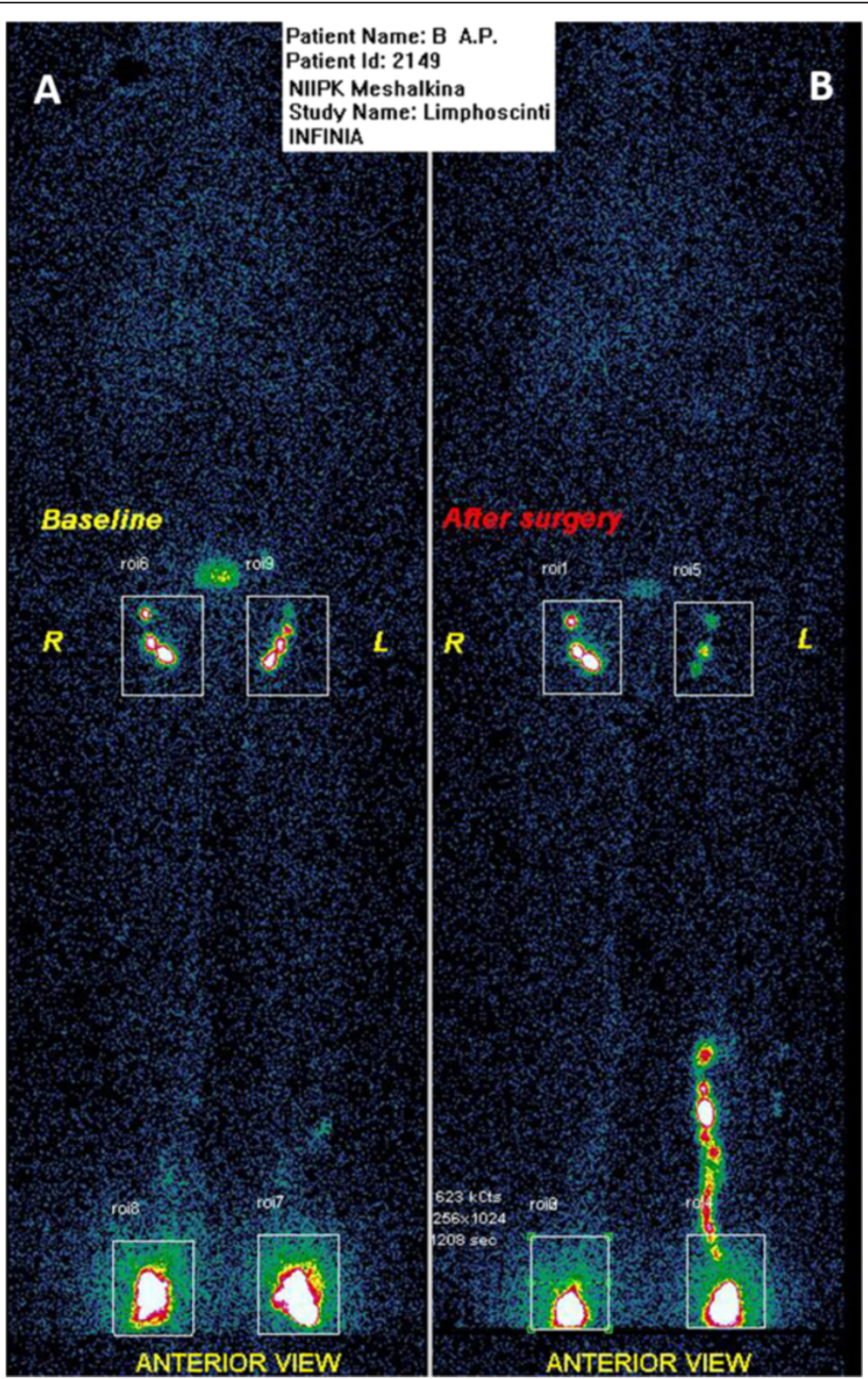

Fig. 2 Lymphoscintigrams: before the surgery (a) and on Day 7 after the open vein harvesting on the left lower limb (b)

and prognostic implications must be the primary outcomes. EVH required more frequent vein repairs than $\mathrm{OVH}$. Minimally invasive vein harvesting techniques reduce visualization of the graft, and are more technically complex. This can potentially lead to reduced vessel integrity. Given the recent finding by Lopes et al. [6] that EVH may be associated with reduced graft patency, this represents a potentially important finding. However, another large cohort study reported no mid-term effect on mortality associated with EVH [7]. Although bridging technique was associated with more minor repairs than $\mathrm{OVH}$, it requires thorough long-term follow-up and provides equivalent long-term outcomes [19]. This indicates that reduced vessel integrity and subsequent vein repair do not affect clinical outcomes, although a formal histological assessment of this hypothesis is required.

In our study, we performed histological examination of vein fragments after both techniques. Morphological studies revealed general wall damage types during venous autogenous graft collection as well as specific issues associated with EVH. The following factors were identified: coagulation of paravascular soft tissues associated with the EVH method, and wall dissection accompanied by layer displacement along the longitudinal axis of the vessel.

In addition to endothelial layer damage, light microscopy revealed a number of other structural manifestations. 
Table 4 Types of structural vein wall damages

\begin{tabular}{llll}
\hline Types of GSV damages & $\begin{array}{l}\text { OVH } \\
(n=83)\end{array}$ & $\begin{array}{l}\text { EVH } \\
(n=78)\end{array}$ & $p$ \\
\hline Focal endothelial layer desquamation & $\begin{array}{l}30 \\
(36.2 \%)\end{array}$ & $\begin{array}{l}23 \\
(29.5 \%)\end{array}$ & 0.37 \\
& $0(0 \%)$ & $5(6.4 \%)$ & 0.02 \\
$\begin{array}{l}\text { Vein wall dissection (without superficial } \\
\text { damage) }\end{array}$ & & & \\
Vertical and horizontal ruptures of the & 23 & 19 & 0.63 \\
internal layer & $(27.7 \%)$ & $(24.4 \%)$ & \\
Focal and diffuse edema of the vein wall & 37 & 32 & 0.65 \\
& $(44.6 \%)$ & $(41 \%)$ & \\
Adhesion of corpuscles to the endothelial & 10 & 12 & 0.54 \\
surface & $(12.1 \%)$ & $(15.4 \%)$ & \\
Parietal thrombi development & $0(0 \%)$ & $1(1.3 \%)$ & 0.30 \\
Paravascular soft tissue coagulation & $0(0 \%)$ & $7(8.9 \%)$ & 0.004 \\
Total GSV samples with identified damages & 45 & 47 & 0.45 \\
& $(54.2 \%)$ & $(60.3 \%)$ & \\
\hline
\end{tabular}

The most frequent of these was corpuscle adhesion to the de-endothelialized surface. This effect might have been the result of damage to the endothelial layer with the development of high thrombogenicity of the subendothelial tissue to circulating platelets. However, taking into account that the anti-thrombotic properties of the vein are comparatively low, there is a high probability of clotting that needs to be prevented by the introduction of heparin during the vein harvesting stage [20].

We evaluated lymphatic drainage in the lower limbs by radionuclide lymphoscintigraphy. We demonstrated the effect of incision length during $\mathrm{OVH}$ on damage to the lymphatic system of the lower limb. Clinical manifestations of lymphatic drainage in the early post-surgical period depend directly on damage to lymphatic drainage function. The aggravation of these clinical manifestations might be accounted for pre-clinical lymphatic drainage function. Thus, lower limb lymphoscintigraphy in the early postsurgical period allows the detection of patients at risk for lymphedema during vein harvesting. A previous study [9] showed that by the end of a 5-year observation period following GSV harvesting, lower limb drainage manifestations increased by more than two-fold (reaching $46.1 \%$ ) compared to those observed at the 2-year observation period. The present study demonstrated that GSV harvesting for CABG causes various degrees of disturbances to the functional state of the lower limb, and that the intensity of the impact on lymphatic drainage function directly depends on the harvesting method used.

The limitations of this study are the single-center design, the short duration of follow up, and the small number cases in which lymphatic drainage in the lower limb was evaluated. Only 41 patients were assessed $(\mathrm{OVH}=18, \mathrm{EVH}=23$ patients). In our study, vein harvesting was carried out at different sites of the lower limb in each group (from the leg in the OVH group and the hip in the EVH group). This is another limitation, but we do not consider it to be serious because tissue damage in the thigh caused by the open method is obviously more traumatic than damage caused by vein harvesting in the leg. Therefore, in our opinion, it is unethical to subject patients to what is known to be a traumatic procedure if it can be avoided. Despite the different techniques of vein harvesting used in both groups, wound closure was performed using cosmetic skin suturing. In our study, we evaluated the early results of operations using the two methods of vein harvesting, such as wound complications, lymphatic drainage of the lower extremities, and histological status of the veins. We did not evaluate the patency of grafts in the long term despite the fact that this is a very important end point of the procedure. It is a limitation of our study and requires further evaluation in the future.

\section{Conclusion}

The data obtained in this study confirm the effectiveness of EVH. GSVs harvested using the endoscopic technique are of comparable quality to those obtained using the open technique. These results were confirmed by histological studies. We demonstrated that EVH reduces the frequency of post-surgical complications and pain in lower limb wounds. At the same time, the impact on the lymphatic system of the lower limbs is significantly lower if the vein is harvested using endoscopic rather than open technique.

\section{Abbreviations}

AR: Absolute risk; CEAP: clinical classification of chronic venous disorders; $\mathrm{Cl}$ : Confidence Interval; EVH: Endoscopic vein harvest method; GSV: Great saphenous vein; OR: Odds ratio; OVH: Open vein harvest method; RPD: Radio pharmaceutical drug; Rs: Spearman ratio of rank correlation.

\section{Competing interests}

The authors declare that they have no competing interests.

\section{Authors' contributions}

AC conceived the study, operated on the patient and reviewed the manuscript. AV reviewed the manuscript, interpreted statistics. OL collected, analyzed and discussed the data. IT prepared the figures, participated in data collection. YK aided in literature search and provided support in the literature discussion, writing the final version of the manuscript. All authors read and approved the final manuscript.

\section{Acknowledgements}

We would like to thank personnel from Novosibirsk Research Institute of Circulation Pathology for their valuable help in collecting data.

Received: 13 March 2015 Accepted: 28 October 2015

Published online: 12 November 2015

\section{References}

1. Raja SG, Haider Z, Ahmad M, Zaman H. Saphenous vein grafts: to use or not to use? Heart Lung Circ. 2004;13:403-9.

2. Andreasen J, Nekrasas V, Dethlefsen C. Endoscopic versus open saphenous vein harvest for coronary artery bypass grafting: a prospective randomized trial. Eur J Cardiothorac Surg. 2008;34:384-9.

3. Paletta CE, Huang DB, Fiore AC, Swartz MT, Rilloraza FL, Gardner JE. Major leg wound complications after saphenous vein harvest for coronary revascularization. Ann Thorac Surg. 2000;70:492-7.

4. Athanasiou T, Aziz O, Skapinakis P, Perunovic B, Hart J, Crossman MC, et al. Leg wound infection after coronary artery bypass grafting: a meta-analysis 
comparing minimally invasive versus conventional vein harvesting. Ann Thorac Surg. 2003;76(6):2141-6.

5. Reed JF. Leg wound infections following greater saphenous vein harvesting: minimally invasive vein harvesting versus conventional vein harvesting. Int J Low Extrem Wounds. 2008;7:210-9.

6. Lopes RD, Hafley GE, Allen KB, Ferguson TB, Peterson ED, Harrington RA et al. Endoscopic versus open vein-graft harvesting in coronary-artery bypass surgery. N Engl J Med. 2009;361:235-44.

7. Ouzounian M, Hassan A, Buth K, MacPherson C, Ali IM, Hirsch GM, et al. Impact of endoscopic versus open saphenous vein harvest techniques on outcomes after coronary artery bypass grafting. Ann Thorac Surg. 2010;89:403-8.

8. Belczak CE, Godoy JM, Cruz Junior AF, Caffaro RA. Lymphoscintigraphic changes after harvesting of the saphenous vein for coronary artery bypass graft. Rev Bras Cir Cardiovasc. 2011;26(3):488-99.

9. Hussaini BE, Lu XG, Wolfe JA, Thatte HS. Evaluation of endoscopic vein extraction on structural and functional viability of saphenous vein endothelium. J Cardiothorac Surg. 2011;6:82-8.

10. Rousou $\sqcup$, Taylor KB, Lu XG, Healey N, Crittenden MD, Khuri SF, et al. Saphenous vein conduits harvested by endoscopic technique exhibit structural and functional damage. Ann Thorac Surg. 2009;87(1):62-70.

11. Allen KB, Griffith GL, Heimansohn DA, Robison RJ, Matheny RG, Schier JJ, et al. Endoscopic Versus Traditional Saphenous Vein Harvesting: A Prospective, Randomized Trial. Ann Thorac Surg. 1998;66:26-32.

12. Chiu KM, Lin TY, Wang MJ, Chu SH. Reduction of carbon dioxide embolism for endoscopic saphenous vein harvesting. Ann Thorac Surg. 2006;81:1697-9.

13. Banks TA, Manetta F, Glick M, Graver LM. Carbon dioxide embolism during minimally invasive vein harvesting. Ann Thorac Surg. 2002;73:296-7.

14. Chavanon O, Tremblay I, Delay D, Bouveret A, Blain R, Perrault LP. Carbon dioxide embolism during endoscopic saphenectomy for coronary artery bypass surgery. J Thorac Cardiovasc Surg. 1999;118:557-8.

15. Martineau A, Arcand G, Couture P, Babin D, Perreault LP, Denault A. Transesophageal echocardiographic diagnosis of carbon dioxide embolism during minimally invasive saphenous vein harvesting and treatment with inhaled epoprostenol. Anesth Analg. 2003;96:962-4 [table of contents].

16. Chernyavsky AM, Lavrenyuk OV, Volkov AM, Terekhov IN. Immediate comparative results of endoscopic and open great saphenous vein harvesting during coronary artery bypass grafting. Blood Circ Pathol Cardiac Surg. 2012;4:15-9.

17. Bonde P, Graham ANJ, MacGowan SW. Endoscopic vein harvest: advantages and limitations. Ann Thorac Surg. 2004;77:2076-82.

18. Simek M, Nemec P, Bruk V, Gwozdziewicz M, Fluger I, Langova K. Postoperative and midterm outcomes of minimally invasive and endoscopic great saphenous vein harvesting for coronary artery bypass grafting - a prospective analysis. Thorac Cardiovasc Surg. 2007;55(7):428-32.

19. Aziz O, Athanasiou T, Panesar SS, Massey-Patel R, Warren O, Kinross J, et al. Does minimally invasive vein harvesting technique affect the quality of the conduit for coronary revascularization? Ann Thorac Surg. 2005;80:2407-14.

20. Brown EN, Kon ZN, Tran R, Burris NS, Gu J, Laird P, et al. Strategies to reduce intraluminal clot formation in endoscopically harvested saphenous veins. J Thorac Cardiovasc Surg. 2007;134:1259-65.

\section{Submit your next manuscript to BioMed Central and take full advantage of:}

- Convenient online submission

- Thorough peer review

- No space constraints or color figure charges

- Immediate publication on acceptance

- Inclusion in PubMed, CAS, Scopus and Google Scholar

- Research which is freely available for redistribution 